\title{
PENGARUH VARIASI GELLING AGENT KARBOMER 934 EKSTRAK ETANOL DAUN JERUK PURUT (Citrus hystrix DC) TERHADAP SIFAT FISIK GEL DAN AKTIVITAS ANTIBAKTERI Staphylococcus aureus
}

${ }^{1}$ Anggun Hari Kusumawati, ${ }^{2}$ Siti Hufi Hutami

${ }^{1}$ Prodi Farmasi Fakultas Teknologi dan Ilmu Komputer Universitas Buana

Perjuangan Karawang (anggunhari@ubpkarawang.ac.id)

${ }^{2}$ Prodi Farmasi Fakultas Teknologi dan Ilmu Komputer Universitas Buana

Perjuangan Karawang (fm15.sitihutami@mhs.ubpkarawang.ac.id)

\begin{abstract}
ABSTRAK
Ekstrak etanolik daun jeruk purut (Citrus hystrix D.C) mempunyai banyak zat khasiat dimana salah satu zat aktif tersebut berkhasiat sebagai antibakteri. Penggunaan ekstrak etanolik dalam bentuk kental sangat tidak efisien dalam pemakaiannya, sehingga perlu dibuat dalam bentuk sediaan topical, misalnya gel. Penggunaan Karbomer 934 sebagai gelling agent dapat meningkatkan konsistensi basis yang akan berpengaruh terhadap pelepasan zat aktif di dalam gel. Penelitian ini bertujuan untuk mengetahui pengaruh variasi kadar basis Karbomer 934 gel ekstrak etanolik daun jeruk purut terhadap sifat fisik gel dan aktivitas antibakteri terhadap Staphylococcus aureus. Gel dibuat dalam 4 formula dengan konsentrasi basis Karbomer 934 yaitu 0,5 \%, 1\%, 1,5\%, dan 2\%. Gel diuji sifat fisik (organolepstis, homogenitas, pH, viskositas, daya lekat, daya sebar, dan uji hedonik) dan daya antibakteri terhadap Staphylococcus aureus. Data dari uji sifat fisik dan pengukuran diameter zona hambat anti bakteri dianalisis dengan statistika Uji Kruskall-Wallis dan Mann-Withney Hasil penelitian dapat disimpulkan bahwa variasi konsentrasi Karbomer 0,5 \%, 1 $\%, 1,5 \%$ dan $2 \%$ sebagai gelling agent gel ekstrak etanol daun jeruk purut berpengaruh terhadap sifat fisik gel dan aktifitas antibakteri terhadap Staphylococcus aureus. Semakin besar konsentrasi Karbomer 934, viskositas semakin besar dengan FI= 3079 cP.s, FII = 8135 cP.s, FIII=13136 cP.s, $F I V=14307 \mathrm{cP} . \mathrm{s}$, menurunkan daya sebar dengan $F I=5.14 \mathrm{~cm}, F I I=4.04 \mathrm{~cm}, F I I I=3.51 \mathrm{~cm}, F I V=$ $3.35 \mathrm{~cm}$, meningkatakan daya lekat dengan $F I=0.79 \mathrm{~cm}, F I I=0.87 \mathrm{~cm}, F I I I=1.05 \mathrm{~cm}, F I V=1.16$ $\mathrm{cm}$ dan menurunkan efektivitas antibakteri dengan $F I=6.4 \mathrm{~cm}, F I I=5.1, F I I I=5.8 \mathrm{~cm}$ dan $F I V=$ $4.9 \mathrm{~cm}$.
\end{abstract}

Kata Kunci : gel, gelling agent, Karbomer 934, Citrus hystrix D.C, Staphylococcus aureus.

\begin{abstract}
ABSTRCT
Ethanolic extract of kaffir lime leaves (Citrus hystrix D.C) Has many active compounds, antimicrobial activity have been reported numerously. Ethanolic extract of Kaffir Lime leaves can't directly exposure to the human skin. It can be increased of skin rash and eritema. The extract can be formulated in topical product like gel preparation. The aim of this work was to determine the effect of variations in base levels of Karbomer $934 \mathrm{gel}$ ethanolic extract of kaffir lime leaves on the physical properties of gel and antibacterial activity against Staphylococcus aureus. The gel is made in 4 formulas with a base concentration of Carbomer 934 which is $0.5 \%, 1 \%, 1.5 \%$, and 2\%. Gel was tested for physical properties (organolepstis, homogeneity, $\mathrm{pH}$, viscosity, adhesion, dispersion, and hedonic test) and antibacterial power to Staphylococcus aureus. Measuring the diameter of the antibacterial inhibition zone after incubation at $37^{\circ} \mathrm{C}$ for 24 hours. Data from the physical properties test and measuring the diameter of the anti-bacterial inhibitory zone were analyzed by statistical with Kruskal-Wallis test and Mann-Withney test. The results of this study concluded that variations in Carbomer 934 concentration as gelling agent gel ethanol extract of kaffir lime leaves had an effect on the physical properties of the gel and antibacterial activity against Staphylococcus aureus. The greater concentration of Carbomer 934, increase the viscosity value with $F I=3079$ cP.s, FII= $8135 \mathrm{cP} . \mathrm{s}, \mathrm{FIII}=13136 \mathrm{cP} . \mathrm{s}, \mathrm{FIV}=14307 \mathrm{cP} . \mathrm{s}$, decrease the spreadability with $F I=5.14 \mathrm{~cm}, \mathrm{FII=}$ $4.04 \mathrm{~cm}, F I I I=3.51 \mathrm{~cm}, F I V=3.35 \mathrm{~cm}$, increase in adhesion with $F I=0.79 \mathrm{~cm}, F I I=0.87 \mathrm{~cm}, F I I I=$ $1.05 \mathrm{~cm}, F I V=1.16 \mathrm{~cm}$ and decrease the effectiveness of the antibacterial with $F I=6.4 \mathrm{~cm}, F I I=$ $5.1, F I I I=5.8 \mathrm{~cm}$ dan $F I V=4.9 \mathrm{~cm}$.
\end{abstract}

Keywords: gel, gelling agent, Carbomer 934, Citrus hystrix D.C, Staphylococcus aureus. 


\section{PENDAHULUAN}

Jeruk purut adalah aneka jeruk yang asli dari Indonesia, Malaysia dan Thailand. Studi sebelumnya menunjukkan bahwa daun tumbuhan ini mengandung senyawa alkaloid, flavonoid, terpenoid, tanin, minyak atsiri dan saponin (Tunjung dkk, 2015). Menurut Miftahendrawati (2014) senyawa yang terdapat dalam daun jeruk purut yang berfungsi sebagai antibakteri adalah alkaloid, flavonoid, minyak atsiri dan tanin. Menurut penelitian sebelumnya yang dilakukan Suyanti Tri (2007) hasil pengujian antibakteri dengan metode difusi agar menggunakan cylinder cup menunjukkan bahwa ekstrak etanol daun jeruk purut pada konsentrasi 20\%, 30\%, 40\%, 50\% memberikan hambatan terhadap pertumbuhan Staphylococcus aureus, yang setara dengan 29 bpj, 31 bpj, 32 bpj, dan 35 bpj kloramfenikol.

Untuk meningkatkan efektivitas terapetik dan kenyamanan dalam penggunaannya, maka ekstrak etanol daun jeruk purut dibuat dalam sediaan gel. Bentuk sediaan gel dapat melekat lebih lama pada kulit. Menurut Rowe, dkk (2009) Salah satu basis yang digunakan dalam pembuatan gel adalah basis Karbomer 934 yang dibuat dalam konsentrasi 0,5-2,0\%. Semakin besar viskositas gel maka akan mempengaruhi sifat fisik dari gel yang akan menyebabkan peningkatan viskositas gel, daya lekat, dan akan menurunkan daya sebar gel (Pramitasari, 2011) dan semakin besar viskositas (konsistensi) gel maka pelepasan obat semakin lambat (Martin dkk, 1993). Sehingga pada penelitian ini bertujuan untuk mengukur variasi konsentrasi gelling agent Karbomer 934 terhadap sifat fisik gel dan aktivitas antibakteri ekstrak etanol daun jeruk purut terhadap Staphylococcus aureus karena akan berhubungan dengan pelepasan zat aktif dalam sediaan.

\section{TINJAUAN PUSTAKA}

Jeruk purut termasuk famili Rutaceae, dimana bagian buah dan daunnya umumnya dipakai oleh masyarakat sebagai obat tradisional. Bagian daun umumnya digunakan untuk mengatasi kelelahan sehabis sakit berat dan juga untuk menambah cita rasa masakan, sedangkan kulitnya digunakan sebagai obat bisul, panas dalam, radang kulit, radang payudara, kulit bersisik, dan kulit mengelupas (Setiawan, 2000). 
Gel adalah sistem dispersi semipadat yang terdiri dari molekul kecil atau besar dalam pembawa air yang memberikan jellylike dengan penambahan dari gelling agent (Ansel, 2011).

Menurut Flory (1953) dalam cit Lu and Jun (1998) karbomer 934 merupakan gelling agent yang sangat umum digunakan dalam produksi kosmetik karena kompatibilitas dan stabilitasnya tinggi. Tidak toksik jika diaplikasikan kekulit dan penyebaran di kulit lebih mudah (Lachman dkk, 1994). Gel dengan gelling agent karbomer 934 memiliki sifat yang baik dalam pelepasan zat aktif' (Madan and Singh, 2010).

\section{METODE PENELITIAN}

\section{Alat dan Bahan}

Alat yang digunakan adalah Viscometer (LAMMYRHEOLOGY), Maserator, Rotatory Evaporator (CECIL), Neraca Analitik (ADAM SCIENTIFIC, Alat Gelas (PYREX), Mikropipet (FISHERBRAND), Pipet tetes, Incubator, Water Bath (CECIL), Autoklaf (ALL-AMERICAN), Laminar Air Flow (LAF) cabinet, Cawan petri, Cawan porselin, Pembakar bunsen, Kawat/jarum Ose, pH meter, Blender, tabung Mc Farland 0.5, Object glass, Alat uji daya sebar, Alat uji daya lekat, Alat uji homogenitas.

Bahan yang digunakan antara lain daun jeruk purut (Citrus hystix D.C.), Bakteri Staphylococcus aureus, Cairan penyari yaitu etanol 96\%, Larutan $\mathrm{NaCl}$, Larutan WFI, Nutrient Agar (NA) sebagai media pertumbuhan bakteri, Karbomer 934, Trietanolamin atau TEA, Tween 80, Span 80, Propylen Glikol, dan Aquadest. 


\section{Prosedur Penelitian}

\section{Pembuatan Formula}

\begin{tabular}{|c|c|c|c|c|c|c|}
\hline \multirow[t]{2}{*}{ Bahan } & \multicolumn{4}{|c|}{ Formula $(\%$ b/v) } & \multirow[b]{2}{*}{ Fungsi } & \multirow{2}{*}{$\begin{array}{c}\text { Kadar } \\
\text { Penggunaan } \\
(\%)\end{array}$} \\
\hline & F1 & F2 & F3 & F4 & & \\
\hline $\begin{array}{l}\text { Ekstrak Daun } \\
\text { Jeruk Purut }\end{array}$ & 1 & 1 & 1 & 1 & Zat Aktif & $>1$ \\
\hline Karbomer 934 & 0.5 & 1 & 1.5 & 2 & Gelling agent & $0,5-2$ \\
\hline Tween 80 & 0.813 & 0.813 & 0.813 & 0.813 & & $1-15$ \\
\hline Span 80 & 0.187 & 0.187 & 0.187 & 0.187 & Emulgator & $1-10$ \\
\hline Propylen glikol & 10 & 10 & 10 & 10 & $\begin{array}{l}\text { Humectant, } \\
\text { stabilizing } \\
\text { agent }\end{array}$ & $\approx 15$ \\
\hline Trietanolamin & 0.5 & 0.5 & 0.5 & 0.5 & Alkalizing & - \\
\hline Aquades & $\begin{array}{l}\text { Ad } \\
100\end{array}$ & $\begin{array}{l}\text { Ad } \\
100\end{array}$ & $\begin{array}{l}\text { Ad } \\
100\end{array}$ & $\begin{array}{l}\text { Ad } \\
100\end{array}$ & Solvent & - \\
\hline
\end{tabular}

Tabel 1. Formulasi gel ekstrak etanol daun jeruk purut dengan perbedaan penambahan Karbomer

934 sebagai gelling agent 


\section{Diagram Alir Penelitian}

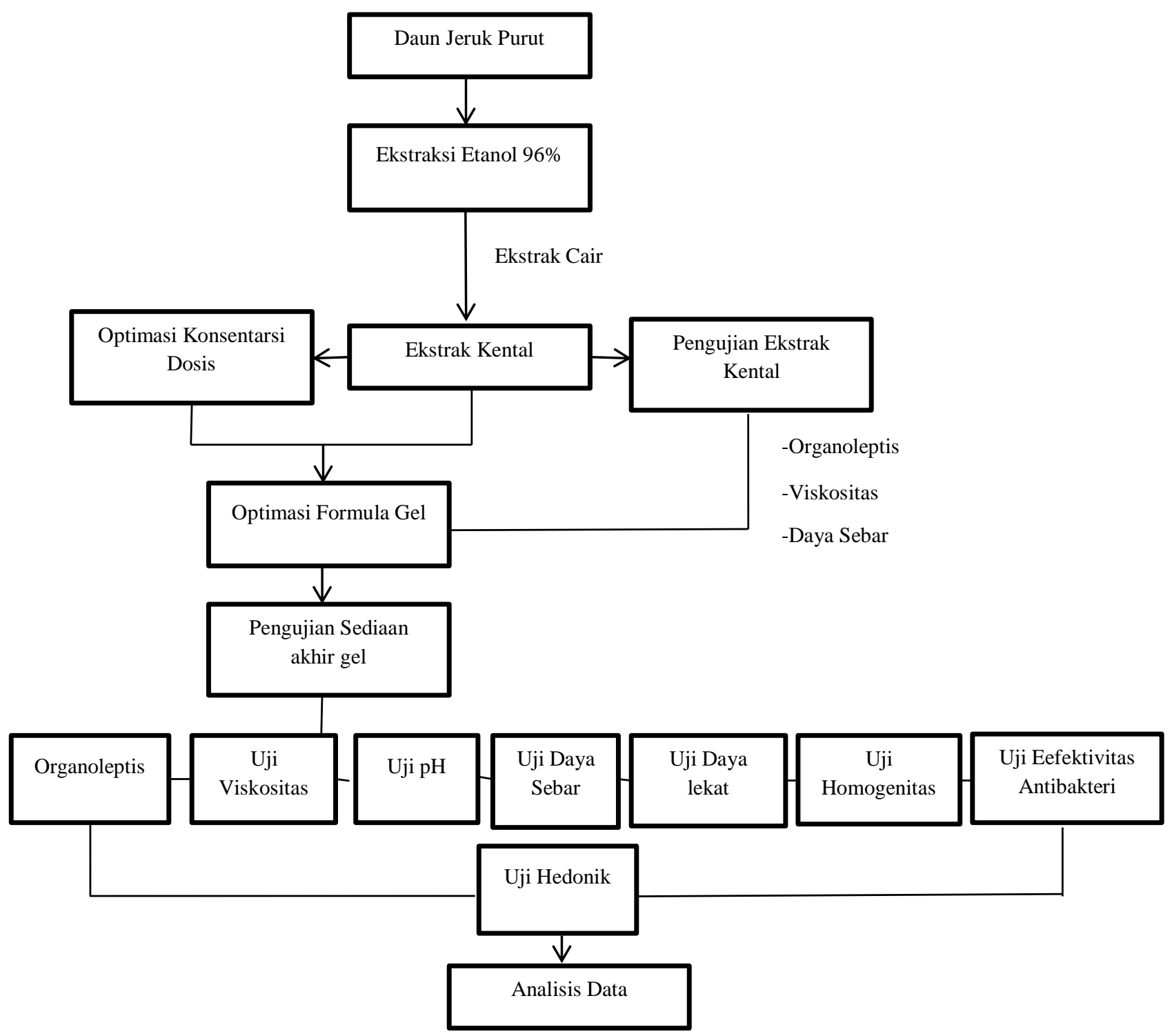

\section{PEMBAHASAN}

\section{Determinasi Tanaman}

Hasil determinasi tersebut menunjukkan bahwa tanaman yang digunakan adalah benar tanaman jeruk purut (Citrus hystrix D.C) dari suku Rutaceae. 
Pembuatan Ekstrak Etanol 96\% Daun Jeruk Purut

\begin{tabular}{|c|c|c|c|c|}
\hline Bobot Daun & $\begin{array}{l}\text { Bobot Basah } \\
\text { (Sortasi) }\end{array}$ & Bobot Kering & Ekstrak & Rendemen \\
\hline $4 \mathrm{Kg}$ & $3500 \mathrm{gr}$ & $800 \mathrm{gr}$ & 119.17 gram & $14.89 \%$ \\
\hline
\end{tabular}

Hasil pada Tabel 2 menunjukkan bahwa ekstrak kental yang didapatkan dari 800 gram simplisia adalah 119.17 gram dengan rendemen ekstrak sebesar $14.89 \%$ sedangkan pada penelitian yang dilakukan Kawiji dkk (2015) menghasilkan rendemen $8.8 \%$ banyaknya rendemen yang dihasilkan akan bergantung pada sifat kepolaran dari senyawa bioaktif yang terkandung dengan pelarut yang digunakan. Lamanya waktu ekstraksi dapat menjadi salah satu faktor yang mempengaruhi rendemen ekstrak, pada penelitian yang dilakukan Amanda dan Kurniaty (2017) rendemen ekstrak yang terbaik didapat pada waktu maserasi hari ke-5 sebesar 23.79 $\%$.

\section{Uji Fisik Ekstrak Kental Etanol Daun Jeruk Purut}

\begin{tabular}{lccc}
\hline \multicolumn{1}{c}{ Organoleptis } & Viskositas & Daya Lekat & Daya Sebar \\
\hline $\begin{array}{l}\text { Bau : khas jeruk } \\
\text { Warna : hijau- kecokelatan } \\
\text { Rasa : pahit }\end{array}$ & $1254 \mathrm{cP}$ & 3.5 detik & $6.4 \mathrm{~cm}$ \\
\hline \multicolumn{2}{c}{ Tabel 3. Hasil Uji Fisik Ekstrak Kental Daun Jeruk Purut } &
\end{tabular}

Tabel 3. Hasil Uji Fisik Ekstrak Kental Daun Jeruk Purut

\section{Pembuatan Gel Ekstrak Etanol Daun Jeruk Purut}

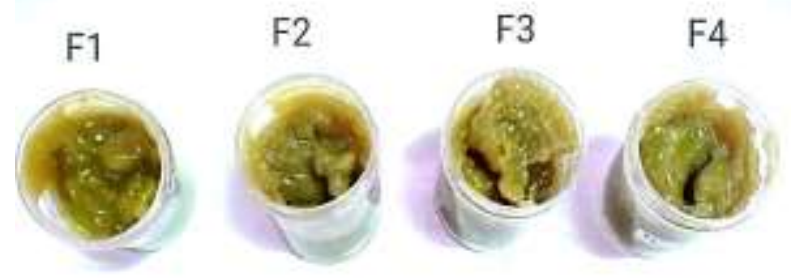

Gambar 1. Hasil Pembuatan Gel Ekstrak Daun Jeruk Purut.

Keterangan :

FI : Konsentrasi Karbomer $=0,5 \%$

FII : Konsentrasi Karbomer $=1 \%$

FIII : Konsentrasi Karbomer =1,5\%

FIV : Konsentrasi Karbomer $=2 \%$ 
Evalusi Gel Ekstrak Daun Jeruk

\begin{tabular}{llllll}
\hline \multicolumn{1}{c}{ Pengujian } & \multicolumn{1}{c}{ Kriteria } & \multicolumn{1}{c}{ FI } & \multicolumn{1}{c}{ FII } & \multicolumn{1}{c}{ FIII } & FIV \\
\hline Organoleptis & & & & & \\
a. Warna & & Hijau- & Hijau- & Hijau- & Hijau- \\
& & Kecokelatan & Kecokelatan & Kecokelatan & Kecokelatan \\
b. Bau & Khas Jeruk & Jeruk & Jeruk & Jeruk & Jeruk \\
c. Tekstur & Kental & Kental & Kental & Kental & Kental \\
d. Dispers & Sedikit & Sedikit & Sedikit & Sedikit & Sedikit \\
\multicolumn{1}{c}{ Koloid } & disperse & disperse & disperse & disperse & disperse \\
Homogenitas & Homogen & Homogen & Homogen & Homogen & Homogen \\
pH & $\mathbf{4 , 5 - 6 , 5}$ & $5.49 \pm 0.47$ & $5.55 \pm 0.36$ & $5.32 \pm 0.24$ & $5.41 \pm 0.28$ \\
Viskositas & $\mathbf{2 0 0 0 - 4 0 0 0 ~ c p ~}$ & $3079 \pm 343$ & $8135 \pm 642$ & $13136 \pm 2570$ & $14307 \pm 1245$ \\
Daya Sebar & $\mathbf{5 - 7 ~ c m ~}$ & $5.14 \pm 0.19$ & $4.04 \pm 0.36$ & $3.51 \pm 0.21$ & $3.35 \pm 0.29$ \\
Daya Lekat & $\mathbf{> 1 ~ d e t i k}$ & $0.79 \pm 0.05$ & $0.87 \pm 0.05$ & $1.05 \pm 0.04$ & $1.16 \pm 0.13$ \\
Aktivitas & & $6.4 \pm 0.5$ & $5.1 \pm 0.7$ & $5.8 \pm 0.3$ & $4.9 \pm 0.8$ \\
Antibakteri & & & & & \\
\hline
\end{tabular}

Tabel 4. Hasil Evaluasi Fisik Gel Ekstrak Daun Jeruk Purut

Evaluasi fisik sediaan gel ekstrak daun jeruk purut secara organoleptis dimaksudkan untuk mengukur sejauh mana suatu produk dapat diterima mutunya dengan menggunakan indra manusia. Gel terbentuk dari dispersi koloid setengah padat dengan fase terdispersi cair dalam medium pendispersi padat, hasil penelitian menunjukkan bahwa sediaan membentuk gel dengan bau khas jeruk dan tekstur kental pada formula I dan II dan sangat kental di formula III dan IV hal ini karena perbedaan konsentrasi yang digunakan yang membuat tekstur sediaan makin kental tiap kenaikan konsentrasi.

Menurut Syamsuni (2005) Gel dikatakan homogen apabila pada saat diraba tidak ditemukan adanya partikel dan memiliki warna yang merata. Hasil uji homogenitas pada tabel 4 menunjukkan bahwa sediaan gel ekstrak daun jeruk purut homogen karena menunjukkan susunan yang homogen, ekstrak terdistribusi merata dan tidak terdapat adanya butiran kasar (Gambar 2). 


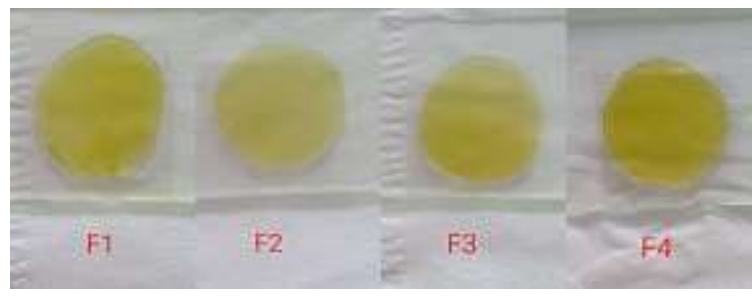

Gambar 2. Hasil Uji Homogenitas

Menurut Naibaho (2013) Rentang pH yang baik pada sediaan gel adalah 4,5 - 6,5. Hasil pengujian pH didapatkan hasil bahwa ke-4 formula sesuai dengan kriteria antara 4,5 - 6,5. Pengukuran $\mathrm{pH}$ didasarkan pada penambahan Trietanolamin (TEA) pada sediaan semakin banyak konsentrasi TEA yang ditambahkan sediaan akan semakin basa. Saat Karbomer didispersikan dengan air Karbomer akan melepaskan sebagian gugus karboksilat dari polimernya sehingga memberikan suasana asam dan memberikan sifat fisik gel yang keruh lalu dengan penambahan basa kuat seperti TEA gugus karboksilat akan dilepaskan secara menyeluruh dan dinetralkan sehingga akan memberikan suasana basa dan efek gel yang jernih.

Menurut Nurahmanto dkk (2017) Viskositas gel yang baik berada pada rentang 50 - 1000 dPa.s, dengan viskositas optimal 200 dPa.s. Pada tabel 4 hasil pengujian viskositas memperlihatkan bahwa terdapat kenaikkan nilai viskositas tiap penambahan konsentrasi, semakin tinggi konsentrasi Karbomer maka viskositas sediaan semakin meningkat. Peningkatan jumlah Karbomer sebagai gelling agent yang digunakan disebabkan karena sifat Karbomer yang mengembang dan matriks yang terbentuk semakin kuat sehingga viskositas akan meningkat.

Menurut Garget dkk (2002) Daya sebar gel yang baik antara 5-7 cm. Hasil menunjukkan bahwa yang memiliki daya sebar yang baik sesuai dengan kriteria adalah Formua I dengan konsentrasi Karbomer 0,5\%. Formula II, Formula III dan Formula IV memiliki daya sebar yang tidak sesuai dengan kriteria. Peningkatan luas daya sebar dipengaruhi oleh besar kecilnya konsentrasi Karbomer yang digunakan dan kekuatan matriks gel yang terbentuk. 
Gambar 3. Hasil Uji Daya Sebar

Berdasarkan hasil yang disajikan pada tabel 10 memperlihatkan bahwa semakin besar konsentrasi Karbomer yang digunakan daya lekat semakin meningkat. Gel yang baik memiliki daya lekat lebih dari 1 detik, karna semakin lama gel merekat pada kulit absorbsi zat aktif akan semakin lama. Pada hasil pengujian ke-4 formula diketahui formula ke-4 lah yang memiliki daya lekat yang baik yaitu lebih dari 1 detik karena konsistensi gel yang sangat kental berbeda dengan formula 1, formula 2 dan formula 3, adanya penambahan ekstrak daun jeruk purut juga memberikan pengaruh terhadap daya lekat.

\begin{tabular}{ccc}
\hline & $\begin{array}{c}\text { Hasil Zona Hambat } \\
\text { Sediaan }(\mathbf{m m})\end{array}$ & $\begin{array}{c}\text { Hasil Zona Hambat K+ } \\
\mathbf{1 \%}(\mathbf{m m})\end{array}$ \\
\hline FI & $6.4 \pm 0.5($ Lemah) & $9.3 \pm 0.8($ Lemah $)$ \\
FII & $5.1 \pm 0.7($ Lemah) & $8.3 \pm 0.6($ Lemah $)$ \\
FIII & $5.8 \pm 0.3($ Lemah $)$ & $7.4 \pm 0.2($ Lemah $)$ \\
FIV & $4.9 \pm 0.8($ Lemah) & $7.4 \pm 1.0($ Lemah $)$ \\
\hline
\end{tabular}

$\overline{\text { Tabel 5. Hasil Uji Aktifitas Antibakteri Gel Ekstrak Daun Jeruk Purut }}$

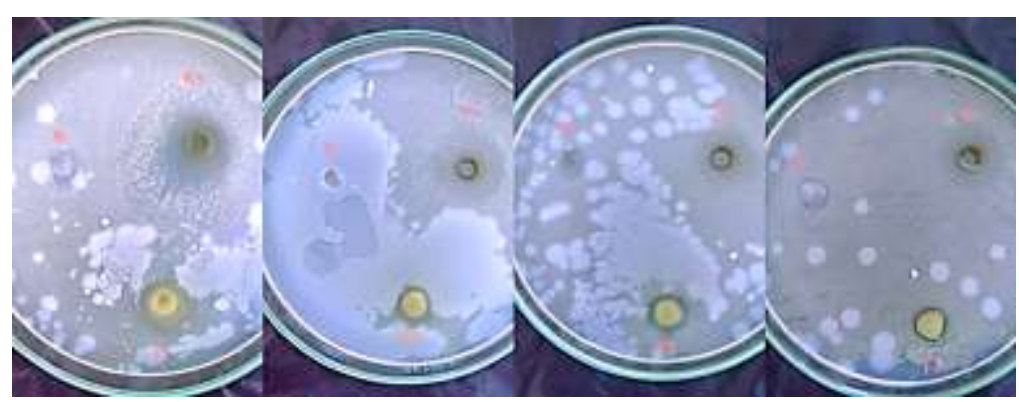

Gambar 4. Hasil Uji Aktifitas Antibakteri Gel Ekstrak Daun Jeruk Purut

Berdasarkan hasil pengujian yang disajikan pada tabel 5 dapat dilihat bahwa zona bening yang dihasilkan dari ke empat formula terbilang lemah dan zona bening yang dihasilkan kontrol positif juga terbilang lemah namun pada kontrol positif 
zona bening yang dihasilkan lebih besar dibandingkan yang sudah dibentuk dalam gel hal ini karena kontrol positif dalam bentuk ekstrak dan memungkinkan jika menaikkan konsentrasi ekstrak zona bening yang akan dihasilkanpun akan semakin besar. Zona bening yang dihasilkan oleh sediaan dipengaruhi oleh konsentrasi basis yan terdapat dalam sediaan semakin besar konsentrasi basis gel Karbomer semakin kecil zona hambat yang dihasilkan, semakin besar konsentrasi Karbomer yang digunakan semakin besar juga matriks polimer yang terbentuk sehingga zat aktif akan terjerat lebih lama di dalam sediaan sehingga penggunaan gelling agent dengan konsentrasi basis besar dimungkinkan untuk penggunaan jangka panjang.

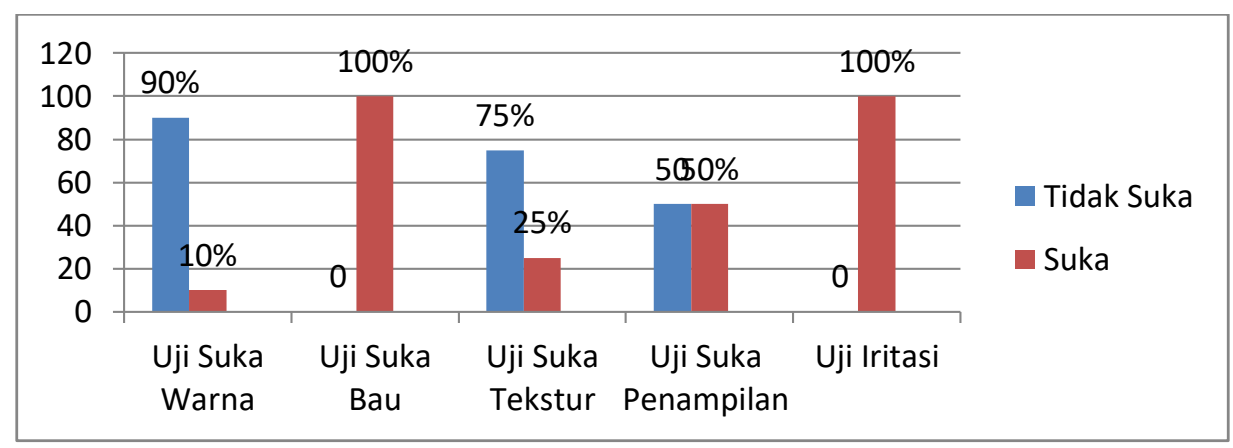

Gambar 5. Diagram uji Hedonik

Uji hedonik atau uji kesukaan dilakukan untuk mengetahui seberapa besar respoden menyukai sediaan yang telah dibuat, pada penelitian ini uji hedonik dilakukan pada 20 orang responden meliputi penilaian terhadap warna, tekstur, bau, penampilan dan iritasi untuk 4 formula yaitu Formula I, Formula II, Formula III dan Formula IV.

\section{Analisis Data}

Hasil uji normalitas menyatakan bahwa data normal dengan $\mathrm{p}$ value $>0,5$ namun tidak homogen dengan $\mathrm{p}$ value $<0,05$ sehingga dilakukan uji alternatif nonparametrik yaitu Kruskall-Walis, hasilnya adalah $\mathrm{p}$ value $<0,05$ yang artinya terdapat perbedaan yang sangat signifikan pada tiap kelompok perlakuan. 


\section{KESIMPULAN}

Berdasarkan penelitian yang telah dilakukan dapat diambil kesimpulan bahwa variasi konsentrasi Karbomer 934 berpengaruh pada sifat fisik gel meliputi organoleptis, $\mathrm{pH}$, homogenitas, viskositas, daya sebar, daya lekat dan aktivitas antibakteri terhadap Staphylococcus aureus.

Formulasi yang memiliki kriteria fisik dan aktifitas antibakteri yang baik untuk sediaan gel ekstrak etanol daun jeruk purut adalah Formula I dengan konsentrasi Karbomer 934 0,5\%, dengan viskositas 3079 cP.s, daya sebar 5.14 cm, aktivitas antibakteri $6.4 \mathrm{~cm}$, hanya saja memiliki daya lekat yang kurang baik $<1$ detik.

\section{DAFTAR PUSTAKA}

Amanda, A., dan Kurniaty, I. 2017. Pengaruh Waktu Maserasi Terhadap Rendemen Zat Antosianin Pewarna Alami Minuman Jelly Dari Terong Ungu. Seminar Nasional Sains dan Teknologi. Universitas Muhamadiyah Jakarta.

Ansel, H., Allen, L., Popovich, N., 2011, Ansel's Pharmaceutical Dosage Forms and Drug Delivery Systems, 9th Edition, Lippincott Williams \& Wilkins, Baltimore.

Kawiji, dkk. 2015. Ekstraksi Maserasi Oleoresin Daun Jeruk Purut (Citrus hystrix DC) : Optimasi Rendemen Dan Pengujian Karakteristik Mutu. AGRITECH, Vol. 35, No. 2, Mei 2015. Universitas Sebelas Maret. Surakarta.

Miftahendarwati, 2014, Efek Antibakteri Ekstrak Daun Jeruk Purut (Citrus hystrix) Terhadap Bakteri Streptococcus mutans (in vitro), Naskah Skripsi, Fakultas Kedokteran Gigi Universitas Hasanudin, Makassar. Tersedia di : http://repository.unhas.ac.id/bitstream/handle/123456789/11578/MIFTAHENDA $\underline{\text { RWATI.pdf? sequence }=1}$

Naibaho, Olivia H. Paulina V.Y. Yamlean, Weny Wiyono., 2013., Pengaruh Basis Salep Terhadap Formulasi Sediaan Salep Ekstrak Daun Kemangi (Ocimun Sanctum L.) Pada Kulit Punggung Kelinci Yang Dibuat Infeksi Staphyloccocus Aureus., Jurnal Ilmiah Farmasi., UNSRAT., Vol 2 N0 02., ISSN 2302-2493.

Nurahmanto D., Mahrifah I.R., Firda R., Imaniah N. dan Rosyidi V.A., 2017, Formulasi Sediaan Gel Dispersi Padat Ibuprofen : Studi Gelling Agent dan Senyawa Peningkat, Ilmiah Manuntung, 3 (1), 96-105.

Pramitasari, R.S., 2011, Pengaruh Komposisi Beeswax dan Carnauba Wax Sebagai Basis Terhadap Kekerasan dan Daya Lekat Sediaan Lipstik Dengan Pelembab Minyak Buah Alpukat (Persea americana Mill.), Skripsi, Universitas Sanata Dharma, Yogyakarta. 
Rowe, R. C., Sheskey, P. J., and Owen, S. C. 2006, Handbook of Pharmaceutical Excipient. Edisi 5, Pharmaceutical Press and American Pharmacist Association.

Satyajit D. Sarker and Lutfun Nahar (eds.). 2012. Natural Products Isolation, Methods in Molecular Biology, vol. 864. Springer Science+Business Media, LLC

Tunjung,W.A.S.,Cinatl, J.,Michaelis, M.,Smales, M. 2015. Anti-Cancer Effect of Kaffir Lime (Citrus hystrix DC) Leaf Extract in Cervical Cancer and Neuroblastoma Cell Lines. Jurnal Prodia Chemistry 14 (2015) : 465 - 468 . Tersedia di : http://www.sciencedirect.com/science/article/pii/S1876619615000637 